\section{Habits of the Hedgehog.}

IN Nature of May ig last (pp. $375^{-76}$ ) you were good enough to notice at length my paper on "The Ancient Legend as to the Hedgehog carrying Fruit upon its Spines," published by the Manchester Literary and Philosophical Society (Memoirs, vol. 63, No. 2). That paper was written. with a view to elicit further evidence for or against the truth of the legend, and for such I asked definitely. Unfortunately, so far no one has communicated such to me. I have, however, just found by accident in Nature Notes for 1904 (vol. I6) two records which I had overlooked, and as both are entirely to the point I desire to direct attention to them.

In one Mr. F. B. Doveton, of Karsfield, Torquay, well known as a poet and musician, writing (p. II8) to inquire whether or not there was any truth in the old legend, adds: "My gardener declares that he has seen the feat performed in an adjacent orchard." In the other Mr. W. H. Warner, of Fyfield, Abingdon, wrote (p. 152): "I well remember, many years ago, meeting with hedgehogs in an Oxfordshire orchard, to the spines of which several apples were sticking. The apples had adhered to the spines, I had little doubt, when the creatures were rolling under the trees. That the hedgehog climbs the apple-tree and carries off the fruit (as country people say it is in the habit of doing) is, of course, absurd."

One would like, of course; further details in corroboration of both these records, but, unfortunately, such are not forthcoming, the two gentlemen in question being now dead. One can, therefore, only note that there seems no reason. whatever to doubt the perfect bona fides of either. One of the records is, it is true, second-hand, but it is contributed by a gentleman of known standing, who clearly was prepared to accept the truth of his informant's statement. The other is a perfectly definite first-hand statement by a contributor who was (I have ascertained) likely to be trustworthy as a field observer.

When writing my article I omitted to mention the not uninteresting fact that the hedgehog, under its old English name of "urchin," enters into the armorial bearings of sevéral English families, either as a charge or as a crest-in the latter case generally on a "mount." Among these is that of Claxton, which bears as its crest an urchin sable, bezantée. The bezants represented originally, without doubt, apples or other fruit stuck upon its spines.

London, October 5 .

Miller Christy.

\section{The Flight of Thistledown.}

IT appears that fully blown thistledown in the sunshine has a positive lifting power, apart from any general upward current of the air. I shall be glad if any readers of NATURE can bring facts to confirm or contradict this statement.

Experiments that give the best result can be carried out as follows:-Find a thoroughly healthy thistle on which the seed is completely ripe and is in process of being shed. By means of tweezers liberate a tuft of the down, and without in any way injuring the symmetry of the whorl take off the seed and the style, which may be recognised through its darker colour. If the tuft in its uninjured condition is liberated in the sunshine on a level plane, it will be found to soar out of sight like a balloon.

One explanation may be that the sun in shining on the fine cilia warms them and creates a small local current of warm air.

I have found that swansdown, which appears to afford a much larger surface for a given weight than NO. 2712 , VOL. IO8] thistledown, does not have the same soaring power. I am not sure that the effect is purely thermal; it may be electrostatic. It is very important that the whorl should be undistorted.

When the tuft is loaded with a seed it appears to be almost neutral, with perhaps a slight lifting power under the best conditions. The whorl and seed in a slight wind will sometimes be carried for several hundred yards, falling and rising in the air-currents. Taking the weight of the seed at 0.5 of a milligram, it is easy to calculate how many tufts would be required to raise $\mathrm{I}$ ton!

College of Technology, Sackville Street, Manchester, September 29.

\section{A Method of Improving Visibility of Distant Objects.}

THE idea may have been suggested before, but I believe it is not generally known and appreciated how very much the power of distinguishing detail in a distant object, and especially of perceiving it in its natural colours, may be improved by the simple device of fitting a small Nicol's prism in the eye-piece end of the observing telescope. The Nicol serves to cut off a great deal of the blue atmospheric "haze" which usually envelops a distant view, and mostly consists of polarised light. Details which are usually lost in the haze, such as the colour of distant rocks or of the vegetation growing upon them, then stands out in a very striking way.

It may also be worth mentioning that the visibility of the horizon at sea, especially in a haze, may often be wonderfully improved by a similar device. In this case the result is due in part to a suppression of the reflection from the surface of the water as seen through the Nicol's prism.

It is hoped that these observations will not be merely a scientific curiosity, but may find a practical application.

C. V. Raman.

S.S. Narkunda, near Aden, September 18.

\section{Gold-coloured Teeth of Sheep.}

IN NATURE of June 9 last (p. 459), recently arrived here, is a communication from Mr. W. J. Lewis Abbott concerning the metallic-looking encrustation occurring on the teeth of sheep. In Proc. Linnean Soc. N.S. Wales (vol. 45 , 1920, p. 324), abstracted in Nature of April 2 I last (p. 249) and reprinted in full in the Chemical News (vol. I22, p. 49), I give a detailed report, with analyses, of this and similar deposits on the teeth of a number of other animals, including man. In no case is the deposit of a metallic nature, but consists entirely of a salivary encrustation composed usually mainly of phosphate of lime with organic matter. The metallic appearance is an optical effect due to the refraction of light by the overlapping thin lammellæ of the deposit.

I should be interested in examining Mr. Abbott's specimen if he will send me one, and reporting the result in NatuRE.

Stephens Street, Pennant Hills, New South Wales, August $x$.

\section{The Constitution of Molecules.}

The remarks attributed to me in NATURE of. October I3 (p. 2ra) give an incorrect impression of what I intended to convey to the meeting. The statement that the molecular heats "are inconsistent with the arrangement which has been adopted to account for chemical valency " was not made.

October I4. 